\title{
Does long-term oxygen therapy affect quality of life in patients with chronic obstructive pulmonary disease and severe hypox- aemia?
}

\author{
A.A. Okubadejo*, E.A. Paul*, P.W. Jones**, J.A. Wedzicha
}

Does long-term oxygen therapy affect quality of life in patients with chronic obstructive pulmonary disease and severe hypoxia? A.A. Okubadejo, E.A. Paul, P.W. Jones, J.A. Wedzicha. CERS Journals 1996.

ABSTRACT: Long-term oxygen therapy (LTOT) improves survival in patients with hypoxaemic chronic obstructive pulmonary disease (COPD), but previous studies using general health measures have shown no effect on quality of life (QoL). In this study, the effect of LTOT on QoL was assessed using a disease-specific health measure, the St George's Respiratory Questionnaire (SGRQ).

Twenty three hypoxaemic COPD patients (15 females and 8 males) were studied before and after starting LTOT: median age 71 (range 47-82) yrs, mean (SD) forced expiratory volume in one second (FEV1) $0.75(0.22) \mathrm{L}$, arterial oxygen tension $\left(\mathrm{Pa}, \mathrm{O}_{2}\right) 6.95(0.75) \mathrm{kPa}$, arterial carbon dioxide tension $\left(\mathrm{Pa}_{\mathrm{a}} \mathrm{CO}_{2}\right) 6.52(1.21)$ $\mathrm{kPa}$. A control group comprised 18 COPD patients (6 females and 12 males) with less severe hypoxaemia: median age 72 (range 58-85) yrs, FEV1 $0.94(0.33) \mathrm{L}, \mathrm{Pa}_{2} \mathrm{O}_{2}$ $8.17(0.94) \mathrm{kPa}, \mathrm{Pa}_{\mathrm{a}} \mathrm{CO}_{2} 6.02(0.75) \mathrm{kPa}$. QoL was measured at baseline, 2 weeks, 3 and 6 months.

The LTOT group had higher SGRQ total scores than controls $(p<0.05)$ at all visits, implying lower QoL. Repeated measures analysis of variance showed no effect of LTOT on QoL over 6 months $(\mathrm{F}=0.43$, $\mathrm{p}=0.79)$.

In this study we detected no change in quality of life using a disease-specific health measure in patients with severe chronic obstructive pulmonary disease using an oxygen concentrator to provide long-term oxygen therapy.

Eur Respir J., 1996, 9, 2335-2339.

\begin{abstract}
*Respiratory Care Unit, London Chest Hospital, London, UK. **Division of Physiological Medicine, St George's Hospital Medical School, London, UK.
\end{abstract}

Correspondence: A.A. Okubadejo

Department of Medicine for the Elderly

Homerton Hospital

Homerton Row

London E9 6SR

UK

\section{Keywords:}

Chronic obstructive pulmonary disease hypoxia

oxygen therapy

quality of life

Received: March 71996

Accepted after revision June 281996
Long-term oxygen therapy (LTOT) is a well-established treatment for patients with chronic obstructive pulmonary disease (COPD) and severe hypoxaemia. Two large, randomized studies, the British Medical Research Council (MRC) study and the Nocturnal Oxygen Therapy Trial (NOTT) study from the USA, published in the early 1980s, established that LTOT for at least $15 \mathrm{~h} \cdot \mathrm{day}^{-1}$ can reduce mortality in these patients [1, 2]. Other studies have shown physiological benefits of LTOT, including reduction of pulmonary hypertension and secondary polycythaemia [3-6], and improvements in neuropsychological function $[7,8]$.

In addition to having a poor prognosis, patients with severe hypoxaemia and COPD suffer considerable functional disability. Several studies have shown that quality of life is impaired in patients with COPD and hypoxaemia [9-11]. Furthermore, in patients with moderateto-severe hypoxaemia, the quality of life score is related to the degree of hypoxaemia when measured using a disease-specific questionnaire [12]. However, the effect of LTOT on quality of life has not been clearly established. In an ancillary study to the NOTT study, there was no improvement in quality of life over 6 months in patients with hypoxic COPD treated with oxygen compared to age-matched controls without COPD [8]. This study used a general health questionnaire, the Sickness
Impact Profile (SIP) [13]. In a recent study, this questionnaire did not discriminate between patients with different levels of hypoxia in contrast to a disease-specific measure whose scores were correlated with arterial oxygen tension $\mathrm{Pa}_{\mathrm{a}} \mathrm{O}_{2}$ [12]. It is possible that the use of an oxygen concentrator for the provision of LTOT might reduce a patients' quality of life by causing problems, such as restricted mobility, noise disturbance, and sore nose or ears from the use of nasal cannulae [14].

The aim of the present study was to assess the effect of LTOT on quality of life in patients with hypoxaemia and COPD using a disease-specific measure of life quality, the St George's Respiratory Questionnaire (SGRQ) [15], as well as the SIP. Quality of life scores for the patients using LTOT were compared with scores for a control group of patients with severe COPD but without severe hypoxaemia, who therefore did not require LTOT. Since emotional dysfunction is common in patients with COPD [16, 17] anxiety and depression were also measured.

\section{Methods}

The patients studied met the standard eligibility criteria for the prescription of LTOT. A group of 23 patients 
(15 females and 8 males) of median age 71 yrs (range 47-82 yrs) were selected from out-patient chest clinics in the East London area. All patients had a diagnosis of COPD, a forced expiratory volume in one second (FEV1) $<1.5 \mathrm{~L}$, and a $P \mathrm{a}_{2} \mathrm{O}_{2}<7.3 \mathrm{kPa}$ when stable or a $P \mathrm{a}, \mathrm{O}_{2}$ $<8.0 \mathrm{kPa}$ with evidence of cor pulmonale (oedema and electrocardiographic (ECG) changes of right ventricular hypertrophy). All patients had been free from acute exacerbations for at least 3 weeks before entry into the study. Blood gas values and spirometry were assessed on two occasions, at least 3 weeks apart, to confirm stability. Exclusion criteria were: age $<45$ yrs; and inability to understand or complete quality of life questionnaires. Patients were assessed with arterialized capillary blood gas estimation [18], spirometry and quality of life questionnaires.

The quality of life questionnaires used were the SGRQ, the SIP and the Hospital Anxiety and Depression Scale (HADS) [19]. The SGRQ produces three component scores, symptoms, activity and impacts, as well as a total score. The SIP has a global score for physical functioning (physical) and for psychosocial functioning (psychosocial), and it also provides an overall total score (total). Each of the scores for the SGRQ and SIP have a possible range of $0-100$, higher scores indicate poorer quality of life. The HADS produces a score for anxiety and a score for depression, higher scores indicate higher levels of anxiety or depression and the maximum for each score is 21 . An individual with a score above 8-10 is likely to suffer from clinically significant anxiety or depression [19].

The patients were assessed at baseline and were then prescribed oxygen concentrators for the provision of LTOT for at least $15 \mathrm{~h} \cdot \mathrm{day}^{-1}$. Patients were reassessed after 2 weeks, 3 and 6 months. Prior to commencing LTOT, all patients were stabilized on optimal medical therapy for COPD. During the study period, patients received normal therapy for COPD and were appropriately treated for exacerbations. Compliance with LTOT was assessed by direct questioning of the patients and by meter readings. Ambulatory oxygen was not prescribed for any of the patients during the course of the study.

It would have been unethical to withhold LTOT from patients with severe hypoxaemia for the proposed duration of the study. Therefore, a control group of 18 patients (6 females and 12 males) with less severe hypoxaemia were chosen from the patients attending the chest clinic at the London Chest Hospital over the same time period. These patients also had COPD, with a FEV1 $<1.5 \mathrm{~L}$, and were hypoxaemic but did not satisfy the British Department of Health criteria for prescription of LTOT [20]. The control group had median age 72 yrs (range 58-85 yrs). These patients were assessed in the same manner and at the same intervals as the study group, but were not prescribed LTOT. None of the control group used ambulatory oxygen or intermittent oxygen from cylinders during the course of the study.

All assessments of both groups were made by the same person. Questionnaires were self-completed under supervision. During the study, none of the patients received home follow-up visits by respiratory health workers, and no patients participated in pulmonary rehabilitation programmes. None of the patients were started on anxiolytic or antidepressant therapy. Patients were not commenced on home nebuliser therapy during the study, nor were they started on long term oral steroids.

The study was approved by the Ethics Committee of the Royal Brompton National Heart and Lung Hospitals, and all patients gave written informed consent to participation in the study.

\section{Statistical analysis}

In this study, scores for anxiety and depression were not normally distibuted, and so the comparison between study group and control group in baseline anxiety and depression scores was made using the Mann-Whitney U-test. The distribution of all other variables approximated to a normal distribution, so that parametric tests were used. Analysis of variance (ANOVA) of repeated measures was used to investigate the effect of oxygen therapy on quality of life.

\section{Results}

\section{Physiological variables}

At the time of enrolment into the study the mean (SD) values for the study group were FEV1 $0.75(0.22) \mathrm{L}$, $\mathrm{Pa}_{2} \mathrm{O}_{2} 6.95$ (0.75) kPa, $\mathrm{Pa}_{2} \mathrm{CO}_{2} 6.52$ (1.21) kPa; values for the control group were FEV1 $0.94(0.33) \mathrm{L}, \mathrm{Pa}_{2} \mathrm{O}_{2}$ 8.17 (0.94), $\mathrm{Pa}_{2} \mathrm{CO}_{2} 6.02(0.75) \mathrm{kPa}$. The values for $\mathrm{Pa}, \mathrm{O}_{2}$, arterial carbon dioxide tension $\left(\mathrm{Pa}_{\mathrm{a}} \mathrm{CO}_{2}\right)$ and $\mathrm{FEV} 1$ are presented in table 1 . The study group had more severe hypoxaemia than the control group $(p<0.001)$. There was no significant change in blood gas values breathing room air or in spirometry during the course of the study either for the study group or the control group.

\section{Mortality}

During the study, four of the study patients and one of the control patients died. Results from those patients who died are not considered in the analysis.

\section{Quality of life measurements}

The mean scores for the SGRQ in both groups throughout the study are presented in table 2, and the corresponding SIP scores in table 3.

Table 1. - Physiological variables for the sudy group $(n=19)$ and control group $(n=17)$

\begin{tabular}{|c|c|c|c|c|}
\hline & Baseline & 2 weeks & 3 months & 6 months \\
\hline \multicolumn{5}{|l|}{ Study group } \\
\hline${\mathrm{Pa}, \mathrm{O}_{2}}_{\mathrm{kPa}}$ & $7.0(0.8)$ & $7.2(0.8)$ & $7.0(0.6)$ & $7.0(0.7)$ \\
\hline $\mathrm{Pa}_{\mathrm{a}, \mathrm{CO}}, \mathrm{kPa}$ & $6.7(1.2)$ & $6.8(0.9)$ & $6.7(0.8)$ & $6.7(1.0)$ \\
\hline $\mathrm{FEV}_{1} \%$ pred & $40(17)$ & 37 (15) & 39 (18) & 38 (17) \\
\hline \multicolumn{5}{|l|}{ Control group } \\
\hline$P{\mathrm{a}, \mathrm{O}_{2}}_{\mathrm{kPa}}$ & $8.3(0.9)$ & $8.2(0.9)$ & $8.2(0.8)$ & $8.0(0.8)$ \\
\hline$P \mathrm{a}_{1} \mathrm{CO}_{2} \mathrm{kPa}$ & $6.0(0.8)$ & $5.9(0.7)$ & $5.8(0.6)$ & $5.9(0.7)$ \\
\hline FEV1 $\%$ pred & 43 (13) & $42(12)$ & 44 (14) & $40(11)$ \\
\hline
\end{tabular}

Values are presented as mean, and $\mathrm{SD}$ in parenthesis. $P_{\mathrm{a}, \mathrm{O}_{2}}$ : arterial oxygen tension; $P \mathrm{a}, \mathrm{CO}_{2}$ : arterial carbon dioxide tension; $\mathrm{FEV}$ : forced expiratory volume in one second; $\%$ pred: percentage of predicted value. 
Table 2. - St George's Respiratory Questionnaire (SGRQ) scores during the course of the study for the study group $(n=19)$ and control group $(n=17)$

\begin{tabular}{|c|c|c|c|c|}
\hline & Baseline & 2 weeks & 3 months & 6 months \\
\hline \multicolumn{5}{|l|}{ Study group } \\
\hline SGRQ Total & $61.8(18.3)$ & $55.0(13.7)$ & $55.9(12.1)$ & $60.5(16.5)$ \\
\hline Symptoms & $71.2(19.6)$ & $74.5(16.7)$ & $74.2(13.9)$ & $75.3(16.1)$ \\
\hline Activities & $68.9(18.7)$ & 70.6(17.9) & $64.7(14.1)$ & $70.7(17.4)$ \\
\hline Impacts & $54.1(25.5)$ & $40.0(18.0)$ & $45.1(18.3)$ & $50.0(21.8)$ \\
\hline \multicolumn{5}{|c|}{ Control group } \\
\hline SGRQ Total & $45.8(15.5)$ & $41.8(17.7)$ & $44.3(17.4)$ & $48.7(17.3)$ \\
\hline Symptoms & $55.4(24.2)$ & $56.2(25.2)$ & $52.9(25.4)$ & $60.8(20.7)$ \\
\hline Activities & $60.5(20.7)$ & $59.2(24.9)$ & $56.8(22.5)$ & $61.9(22.9)$ \\
\hline Impacts & $34.1(17.1)$ & $27.5(16.8)$ & $34.4(18.1)$ & $37.4(18.2)$ \\
\hline
\end{tabular}

Values are presented as mean, and SD in parenthesis.

Table 3. - Sickness Impact Profile (SIP) scores during the course of the study for the study group $(n=19)$ and control group $(n=17)$

\begin{tabular}{lllll}
\hline & Baseline & 2 weeks & 3 months & 6 months \\
\hline $\begin{array}{l}\text { Study group } \\
\text { SIP Total }\end{array}$ & $17.9(8.5)$ & $16.9(8.6)$ & $16.0(7.0)$ & $18.2(9.1)$ \\
$\begin{array}{l}\text { Physical } \\
\text { Psychosocial }\end{array}$ & $15.0(9.2)$ & $18.7(10.1)$ & $17.0(7.1)$ & $18.0(9.5)$ \\
& & & & \\
Control group & & & & \\
SIP Total & $10.9(8.0)$ & $8.0(6.0)$ & $7.8(6.5)$ & $8.6(6.4)$ \\
Physical & $10.3(9.4)$ & $8.6(6.8)$ & $8.4(8.7)$ & $9.1(8.3)$ \\
Psychosocial & $9.1(8.4)$ & $4.7(5.2)$ & $5.1(5.3)$ & $6.2(5.3)$ \\
\hline
\end{tabular}

Values are presented as mean, and SD in parenthesis.

At the start of the study, the mean (SD) SGRQ Total Scores were 61.8 (18.3) for the study group and 45.8 (15.5) for the control group, implying that the study group, with more severe hypoxaemia, had a significantly worse quality of life $(p=0.008)$. Similarly, the SIP Total Score at the start of the study, 17.9 in the study group and 10.9 in the control group, again suggested that the study group had a significantly worse quality of life $(\mathrm{p}=0.016)$.

After 2 weeks of treatment, the study group had a mean (SD) improvement in SGRQ Total Score of 6.8 (12.7) compared to an improvement of 4.0 (10.7) in the control group. This improvement was not significantly different in the two groups $(\mathrm{p}=0.48)$. After 6 months of treatment, the study group had a very small improvement of 1.3 (14.5) in the SGRQ total score, which was not statistically significant $(\mathrm{p}=0.69)$. This was not significantly different from the mean deterioration in SGRQ total score seen in the control group of 2.9 (13.4) over the same time period $(p=0.38)$. Repeated measures ANOVA showed no statistically significant effect of LTOT on SGRQ total score over the 6 months $(p=0.79)$.

A similar picture was seen with the SIP scores. After 2 weeks of treatment, the study group had a small improvement in SIP total score of 1.0 (5.7) compared to an improvement of 2.9 (3.1) in the control group. The improvement was not significantly different between the two groups $(p=0.11)$. After 6 months of treatment, there was no significant change in the mean SIP total score for the study group $(\mathrm{p}=0.84)$. This change was not significantly different from the small deterioration in SIP score seen in the control group over the same time period: mean deterioration in SIP total for the study group 0.3 (6.9); mean improvement in the control group $2.1(4.0)(p=0.21)$. ANOVA for repeated measures showed no statistically significant effect of LTOT on SIP total score over the 6 months $(p=0.74)$.

No significant correlations were found between changes in $\mathrm{Pa}, \mathrm{O}_{2}$ and changes in quality of life scores.

\section{Emotional dysfunction}

The anxiety scores in the study group were significantly higher at baseline compared to the control group. The median anxiety score for the study group was 7 (interquartile range 4-10); whereas, the median score for the control group was $3(1-7)(\mathrm{p}=0.006)$. After 6 months of LTOT, the study group had a significant improvement in anxiety score compared to controls: study group -0.9 (4.7); control group $+1.8(2.3)(\mathrm{p}=0.034)$.

The depression score in the study group at baseline was not significantly different from that of the control group: study group median score 6 (interquartile range $3-9)$; control group $4(3-6)(p=0.077)$. The mean change in depression scores after 6 months was not significantly different between groups: study group +0.7 (2.6); control group $+1.2(2.9)(\mathrm{p}=0.64)$.

\section{Oxygen use}

Mean (SD) daily use of the oxygen concentrators in the study patients was 16.7 (3.7) $\mathrm{h}$ according to meter readings and $17.1(2.9) \mathrm{h}$ on direct questioning of the patients. The median flow rate of oxygen used was 2 $\mathrm{L} \cdot \mathrm{min}^{-1}$ (range $1-4 \mathrm{~L} \cdot \mathrm{min}^{-1}$ ). The mean (SD) $\mathrm{Pa}, \mathrm{O}_{2}$ while using oxygen at the prescribed flow rate was $8.77(0.59)$ $\mathrm{kPa}$.

\section{Discussion}

Long-term oxygen therapy has a beneficial effect on survival in patients with COPD and severe hypoxaemia [1, 2]. This study supports the view that LTOT provided by an oxygen concentrator does not adversely affect quality of life. Patients receiving LTOT had a slightly greater improvement in their quality of life compared to the control group, but this was not statistically significant during the study period. The compliance measurements in the study group suggest that the patients used enough oxygen to expect some benefit in terms of survival.

The present findings are in general agreement with previous studies into the effect of LTOT on quality of life. In the NOTT study using a general health measure (the SIP), a statistically significant improvement in quality of life was shown after 6 months, when considering those patients receiving continuous oxygen and those patients receiving only nocturnal oxygen as a combined group [2]. However, the changes were not large and the authors suggested that improvements might have been 
due to the more intensive medical and nursing care which the patients received. Data were not given for the continuous oxygen therapy group alone. The NOTT study did not include untreated controls, but in a separate analysis the NOTT study patients receiving either continuous oxygen therapy or nocturnal oxygen therapy were compared to normal people without COPD of the same age and social background [8]. In the latter study, the SIP was used to measure quality of life, and the Profile of Mood States (POMS) [21] to measure total mood disturbance. The authors reported no significant difference between groups in their changes in score from the POMS or the SIP. In one uncontrolled study there was no effect of LTOT on general activity and independence, depression or coping skills over a 6 month period [22]. However, another uncontrolled study showed that $83 \%$ of patients with an oxygen concentrator for the provision of LTOT felt that their general wellbeing had improved because of the treatment [23].

The findings of the NOTT study in relation to quality of life emphasize the importance of a control group, but this raises ethical difficulties. As the benefits of LTOT on survival are proven, it would not have been ethically acceptable to withhold LTOT for 6 months from patients who had a $P \mathrm{a}, \mathrm{O}_{2}<7.3 \mathrm{kPa}$. In the present study, the patient group was selected on the basis of severe hypoxaemia, whereas the control group had less severe hypoxaemia but were otherwise closely matched to the LTOT patients, in practice the difference in $\mathrm{Pa}, \mathrm{O}_{2}$ was only $1.3 \mathrm{kPa}$.

There are a few reasons why we may have failed to detect a real quality of life gain with LTOT. Firstly, the questionnaire may not have been appropriate, although the SGRQ has been developed and validated for COPD, and has recently been shown to correlate with degree of hypoxaemia [12]. Secondly, the questionnaire may have been unresponsive, but the SGRQ has been shown to respond to spontaneous changes in health over time [15], and has recently been shown to respond to the use of nasal intermittent positive pressure ventilation in patients with hypercapnic, hypoxaemic COPD [24]. Thirdly, the study may have had insufficient power to detect a small improvement in quality of life. A change of four points on the SGRQ total score is thought to be significant [25]. To have a $95 \%$ chance of detecting such a change compared to the control group, we calculate that a study involving 300 patients treated with LTOT would be required. We conclude that any quality of life gains with LTOT are small. The question of whether certain subgroups of patients may benefit in terms of quality of life arises. We were unable to find any particular group which had a clear benefit. Quality of life changes were not related to the degree of hypercapnia, FEV1 or age in this study. Furthermore, when each component of the SGRQ and the SIP was considered, there were no statistically significant differences between the study group and the control group in terms of the mean change after 6 months in any component score.

Patients with COPD and severe hypoxaemia may suffer from anxiety and depression, and this is associated with decreased exercise tolerance [26]. In this study, the more severely hypoxaemic group initially had higher mean scores for anxiety and depression than the control group. After six months, the study group had become less anxious and the control group had become more anxious. The mean change in anxiety scores was statistically significant between groups. However, the suggestion that LTOT may have a beneficial effect on anxiety levels should be treated with caution, in view of the smallness of the effect. Depression scores after 6 months were higher both in the study and control groups, and there was no significant difference between groups in terms of changes in mean depression score.

The selection of a control group was difficult in this study. As mentioned previously, it would have been unethical to withhold oxygen therapy from severely hypoxaemic patients. The use of a group of patients with less severe hypoxaemia as a control group means that the study is unable to demonstrate whether LTOT prevents a deterioration in certain consequences of hypoxaemia, such as oedema, muscular atrophy and neuropsychiatric impairment. Another limitation of the present study is the fact that the LTOT group used an oxygen concentrator, whereas the control group did not. It is possible that the patients in the LTOT group were more restricted in activities of daily living than the control group as a result of using an oxygen concentrator, since this might be expected to make them stay at home more and reduce their overall exercise level. Therefore, the study design does not allow us to comment on the effect of LTOT on quality of life if LTOT is provided by other delivery methods allowing greater mobility, such as liquid oxygen cylinders.

In conclusion, the present findings add to the evidence that long-term oxygen therapy does not reduce quality of life in patients with chronic obstructive pulmonary disease complicated by severe hypoxaemia but, equally, long-term oxygen therapy does not seem to have a major beneficial effect on quality of life. In this study, patients were not using ambulatory oxygen therapy. It is possible that the facility to use ambulatory oxygen might improve quality of life in these patients [27], although in the Nocturnal Oxygen Therapy Trial study patients did use ambulatory oxygen and no benefit on quality of life was shown [8].

Acknowledgements: The authors would like to thank J. Moore-Gillon, A.C. Davidson, and C.M. Roberts for allowing us to study their patients.

\section{References}

1. MRC Working Party. Long-term domiciliary oxygen in chronic hypoxic cor pulmonale complicating chronic bronchitis and emphysema. Lancet 1981; i: 681-686.

2. Nocturnal Oxygen Therapy Group. Continuous or nocturnal oxygen therapy in hypoxemic chronic obstructive lung disease: a clinical trial. Ann Intern Med 1980; 93: 391-398.

3. Levine BE, Bigelow DV, Hamstra RD, et al. The role of long-term continuous oxygen administration in patients with chronic airway obstruction and hypoxaemia. Ann Intern Med 1967; 66: 639-650.

4. Abraham AS, Cole RR, Bishop JM. Reversal of pulmonary hypertension by prolonged oxygen administration to patients with chronic bronchitis. Clin Res 1968; 23: $147-157$. 
5. Petty TL, Finigan MM. The clinical evaluation of prolonged ambulatory oxygen therapy in patients with chronic airway obstruction. Am J Med 1968; 45: 242-252.

6. Stark RD, Finnegan P, Bishop JM. Long-term domiciliary oxygen in chronic bronchitis and pulmonary hypertension. Br Med J 1973; 3: 467-470.

7. Krop HD, Block AJ, Cohen E. Neuropsychological effects of continuous oxygen therapy in chronic obstructive pulmonary disease. Chest 1973; 64: 317-322.

8. Heaton RK, Grant I, McSweeney AJ, et al. Psychologic effects of continuous and nocturnal oxygen therapy in hypoxemic chronic obstructive pulmonary disease. Arch Intern Med 1983; 143: 1941-1947.

9. McSweeney AJ, Grant I, Heaton RK, Adams KM, Timms RM. Life quality of patients with chronic obstructive pulmonary disease. Arch Intern Med 1982; 142: 473478.

10. Prigatano GP, Wright EC, Levin D. Quality of life and its predictors in patients with mild hypoxemia and chronic obstructive pulmonary disease. Arch Intern Med 1984; 144: 1613-1619.

11. Guyatt G, Townsend M, Berman L, Pugsley S. Quality of life in patients with chronic airflow limitation. $\mathrm{Br} \mathrm{J}$ Dis Chest 1987; 81: 45-54.

12. Okubadejo AA, Jones PW, Wedzicha JA. Quality of life in patients with chronic obstructive pulmonary disease and severe hypoxaemia. Thorax 1996; 51: 44-47.

13. Bergner M, Bobbitt RA, Carter WB, Gilson BS. The Sickness Impact Profile: development and final revision of a health status measure. Med Care 1981; 19: 787-805.

14. Restrick LJ, Paul EA, Braid GM, Cullinan P, MooreGillon J, Wedzicha JA. Assessment and follow-up of patients prescribed long term oxygen treatment. Thorax 1993; 48: 708-713.

15. Jones PW, Quirk FH, Baveystock CM, Littlejohns P. A self-complete measure of health status for chronic airflow limitation: the St George's Respiratory Questionnaire. Am Rev Respir Dis 1992; 145: 1321-1327.
16. Light RW, Merrill EJ, Despars JA, Gordon GH, Mutalipassi LR. Prevalence of depression and anxiety in patients with COPD: relationship to functional capacity. Chest 1985; 87: 35-38.

17. Stewart AL, Greenfield S, Hays RD, et al. Functional status and well-being of patients with chronic conditions: results from the medical outcomes study. JAMA 1989; 262: 907-913.

18. Pitkin AD, Roberts CM, Wedzicha JA. Arterialised earlobe blood gas analysis: an under-used technique. Thorax 1994; 49: 364-366.

19. Zigmund AS, Snaith RP. The Hospital Anxiety and Depression Scale. Acta Psychiatr Scand 1983; 67: 361-370.

20. Drug Tariff, HMSO. February 1993; X: 282-285.

21. McNair DM, Lorr M, Droppelman LF. EDITS manual for the Profile of Mood States. San Diego, Educational and Industrial Testing Service 1971.

22. Lahdensuo A, Ojanen M, Ahonen A, et al. Psychosocial effects of continuous oxygen therapy in hypoxaemic chronic obstructive pulmonary disease patients. Eur Respir J 1989; 2: 977-980.

23. Dilworth JP, Higgs CMB, Jones PA, White RJ. Acceptability of oxygen concentrators: the patient's view. $\mathrm{BrJ} \mathrm{Gen}$ Pract 1990; 40: 415-417.

24. Meecham Jones DJ, Paul EA, Jones PW, Wedzicha JA. Nasal pressure support ventilation plus oxygen compared with oxygen therapy alone in hypercapnic COPD. Am J Respir Crit Care Med 1995; 152: 538-544.

25. Jones PW, Quirk FH, Baveystock CM. The St George's Respiratory Questionnaire. Respir Med 1991; 85 (Suppl. B): 25-31.

26. Morgan AD, Peck DF, Buchanan DR, McHardy GJR. Effects of attitudes and beliefs on exercise tolerance in chronic bronchitis. Br Med J 1983; 286: 171-173.

27. Lock SH, Paul EA, Rudd RM, Wedzicha JA. Portable oxygen therapy: assessment and usage. Resp Med 1991; 85: 407-412. 